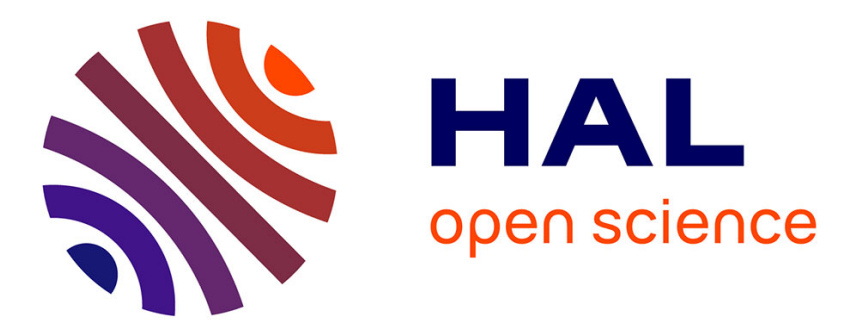

\title{
When cost improvements harm consumers
}

Nicolas Gruyer, Philippe Bontems

\section{To cite this version:}

Nicolas Gruyer, Philippe Bontems. When cost improvements harm consumers. Review of Industrial

Organization, 2007, 30 (1), pp 63-79. 10.1007/s11151-007-9126-z . hal-01021576

\section{HAL Id: hal-01021576 \\ https://hal-enac.archives-ouvertes.fr/hal-01021576}

Submitted on 17 Jul 2014

HAL is a multi-disciplinary open access archive for the deposit and dissemination of scientific research documents, whether they are published or not. The documents may come from teaching and research institutions in France or abroad, or from public or private research centers.
L'archive ouverte pluridisciplinaire HAL, est destinée au dépôt et à la diffusion de documents scientifiques de niveau recherche, publiés ou non, émanant des établissements d'enseignement et de recherche français ou étrangers, des laboratoires publics ou privés. 


\title{
When cost improvements harm consumers
}

\author{
Nicolas Gruyer* \\ Philippe Bontems ${ }^{\dagger}$
}

April 3, 2006

\begin{abstract}
This paper demonstrates that in a vertical structure, improving cost efficiency might sometimes be detrimental to consumers, by increasing market price. This is in stark contrast to the standard result in oligopoly theory which suggests that the surplus generated by any efficiency gain in production is shared between firms and final consumers, depending on the degree of market power. These results are applied in contexts such as international trade, diffusion of knowledge and techniques and government intervention through income support programs.
\end{abstract}

JEL : L11, L12

Key-words: oligopsonists, retail, vertical structure, cost pass-through.

*LEEA-Enac, 7 avenue Edouard Belin, BP4005, 31055 Toulouse Cedex 4. Phone number: 33 (0)5 621740 29, Fax: 33 (0)5 621740 17. gruyer@recherche.enac.fr.

†Université de Toulouse (INRA, IDEI). 


\section{Introduction}

This paper demonstrates that in a vertical structure improving cost efficiency might sometimes be detrimental to consumers, by increasing market price. This is in stark contrast to the standard result in oligopoly theory which tells us that the surplus generated by any efficiency gain in production is shared between the oligopoly and the final consumers, depending on the degree of market power (see for instance Stennek and Verboven $([6])$ for a recent survey of the literature). ${ }^{1}$

More precisely, we consider a group of retailer oligopolists buying a homogenous product from an upstream sector composed of numerous firms. Some of the upstream firms can produce at a low cost but their total production capacity $K$ is fixed in the short term. If initially this production capacity is low enough (for a given demand), then, at the equilibrium, retailers find interesting to procure the good not only from these efficient producers but also from less efficient upstream firms. Denote total production by $Q$. Imagine that for some reasons the efficient producers' total capacity $K$ increases sufficiently. It may appear that retailers find profitable to decrease their orders from $Q$ to $K$. Indeed, by limiting globally their orders at $K$, they stop buying from inefficient upstream firms in order to decrease their procurement costs. If this increase in $K$ is not too large, total production falls and the harsh consequence for consumers is that retail price increases although the procurement price for the oligopoly decreases. In such a situation, a cost efficiency improvement does not benefit consumers at all.

The phenomenon we exhibit has potential implications in several fields. For instance, our basic setting can be interpreted as a situation where high-cost national producers are protected from lowcost foreign producers by an import quota $K$. Starting from a situation where retailers buy products both from national and foreign producers, a small increase in the import quota might not be in the interest of consumers, contrary to the intuition. Indeed, this would allow retailers to refrain from buying to national producers and to coordinate on a smaller equilibrium quantity.

Also, this paper formalizes the idea that technological progress in the upstream sector might yield to opposite patterns concerning final and intermediate prices, at least temporarily. This raises

\footnotetext{
${ }^{1}$ See also Bulow and Pfleiderer ([1]) for an earlier reference on the monopoly case.
} 
concerns on the impact of public support (e.g. public R\&D or subsidies for cost-reducing investments) aimed at reducing upstream producers' production costs. For instance, in agriculture, it is common for governments, both in the US and in Europe, to finance public R\&D that benefits to agricultural producers (Hamilton and Sunding ([2])). It is also common to subsidize improvements in production technology (irrigation). In the context of our model, the impact of public aid is to allow for a limited number of producers (due to budget constraints) to switch from a given technology to a less costly one. This would correspond to an increase in $K$. Our result suggests that if this increase in $K$ is small, then the only impact is to increase the income of subsidized producers. When this increase in $K$ is large, then the improvement in cost efficiency is perfectly transferred to retailers and consumers. However, for intermediate values, the improvement in cost efficiency is perfectly transferred to retailers whereas consumers have to pay a higher retail price.

As noted above, our result contrasts with the conclusions established in the standard microeconomics textbooks (see e.g. Pindyck and Rubinfeld ([4])). Consider for simplicity the situation of constant marginal costs. In case of perfect competition, the pass-on of industry-wide cost savings to consumers is usually complete, except when there exist some capacity constraints. For the monopoly and the oligopoly case, this pass-on is commonly incomplete, depending on the market structure. In any case, the impact of cost savings is always reported to be positive for consumers. ${ }^{2}$ In this paper, we exhibit a setting where this impact is potentially negative.

The paper is organized as follows. Section 2 lays down assumptions and notations. Section 3 is devoted to the monopoly case while we extend our main result to the oligopoly situation in section 4 . Finally, in the last section we apply our results in other contexts such as international trade, diffusion of knowledge and techniques and government intervention through income support programs.

\section{The model}

Consider a vertical structure composed of upstream producers and downstream retailers. Upstream manufacturers produce a homogenous product which is then transformed by retailers and sold to final

\footnotetext{
${ }^{2}$ For a recent detailed discussion on the determinants of the pass-on of cost savings, see the literature on merger controls, for example Stennek and Verboven ([6]) and Ten Kate and Niels ([3]). For an application to the case of mergers in the food retailing sector, see Barros, Britto and De Lucena ([5]).
} 
consumers. The upstream sector is heterogenous in the sense that a fraction of producers is able to produce at constant marginal $\operatorname{cost} c_{1}$. The total production capacity of this group of individual producers is limited and denoted by $K$. The rest of producers face a constant marginal cost $c_{2}>c_{1}>$ 0 . The total capacity of high-cost producers is sufficiently high so that retailers are never constrained in quantity at the equilibrium.

Upstream producers face a set of $N$ symmetric retailers. Marginal distribution cost is assumed to be constant and hence w.l.o.g. we set it to zero. The final (inverse) demand is $P(Q)=a-b Q$ where $Q=\sum q_{i}$ with $q_{i}$ the production of retailer $i{ }^{3}$ We assume that $b>0$ and $a>c_{2}$. We model retailers competition by assuming that they simultaneously choose the quantities offered on the final market while anticipating that the final price will be established to $P(Q)$. We assume that upstream producers are sufficiently numerous so that the upstream market can be considered as perfectly competitive on the supply side: the supply function is denoted $w(Q)$ and is defined by

$$
w(Q)=\left\{\begin{array}{c}
c_{1} \text { if } Q \leq K \\
c_{2} \text { otherwise }
\end{array}\right.
$$

Consequently, the profit function of retailer $i$ can be written as follows

$$
\pi_{i}=[P(Q)-w(Q)] q_{i}
$$

The difference with standard Cournot models is that here each retailer's cost function does depend on the quantity chosen by all the retailers. If the total quantity is less than $K$, the competition between the upstream low-cost producers is fierce enough to drive the procurement price of the good to their marginal cost $c_{1}$. In contrast, if the total quantity exceeds $K$, the procurement price of the good rises to the high marginal cost $c_{2}$. In this case, low-cost producers are able to extract a rent equal to $c_{2}-c_{1}$ per unit. While this assumption may appear inappropriate for some industries, it seems to be a reasonable one if retailers are numerous enough or if the product is sold via spot markets.

\footnotetext{
${ }^{3}$ This assumption can be easily relaxed by only requiring that whatever $Q$ and $q$ positive, we have $q P^{\prime \prime}(q+Q)+$ $P^{\prime}(q+Q) \leq 0$. An usual assumption when using Cournot style models with constant marginal cost is to require that $q P(q+Q)$ is concave, so that the firms' reaction functions are unambiguously defined: When $P$ is twice differentiable, this condition is equivalent to having $q P^{\prime \prime}(q+Q)+2 P^{\prime}(q+Q) \leq 0$, whatever $Q$ and $q$ positive. So, our condition, while having the same "flavor", is a bit more demanding.

Yet, our goal in this paper is to highlight the intuition behing our model, while staying as simple as possible. As our qualitative results extend to more general demand functions, we chose to expose them through simple linear demand functions.
} 
Our analysis is thus applicable to markets where retailers, for whatsoever reason, are not able to price discriminate upstream producers.

\section{The monopoly case}

In this section, we abstract from strategic interaction between retailers by focusing on the monopoly case $(N=1)$. The interest of this restriction is that it allows for a simple graphical analysis of our main result. The monopoly profit function is $\pi(q)=[P(q)-w(q)] q$ which can be rewritten as

$$
\pi(q)=\left\{\begin{array}{c}
{\left[a-b q-c_{1}\right] q \text { if } q \leq K} \\
{\left[a-b q-c_{2}\right] q \text { otherwise }}
\end{array}\right.
$$

Whenever the monopoly orders a quantity higher than $K$, it suffers from a high marginal procurement cost $c_{2}$.

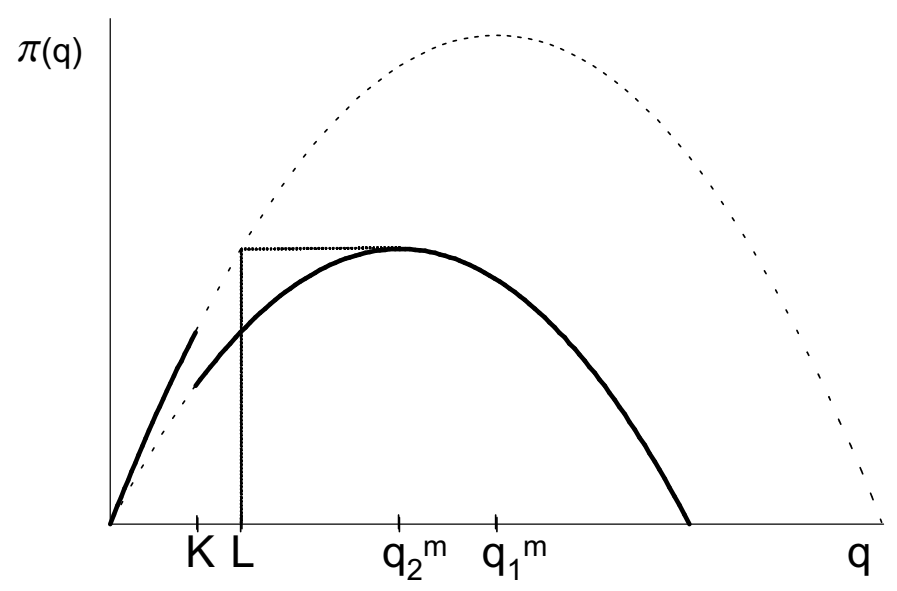

Figure 1: Profit function $\pi(q)$ for low values of $K$.

Figures 1, 2 and 3 present the profit function $\pi(q)$ according to different values for $K$. This profit function is draw from two underlying virtual profit functions. The first one corresponds to the monopoly facing a marginal cost equal to $c_{2}$ (we label it a $c_{2}$-monopoly) and the other one for $c_{1}$. The optimal quantity for a $c_{i}$-monopoly is denoted $q_{i}^{m}$ and we clearly have $q_{2}^{m}<q_{1}^{m}$.

More precisely, figure1 presents the case when $K$ is low enough. In this case, the monopoly has to strongly restrict the quantity sold in order to benefit from a low procurement cost. It appears that going beyond the capacity constraint $K$ by ordering from both low and high-cost producers enables 


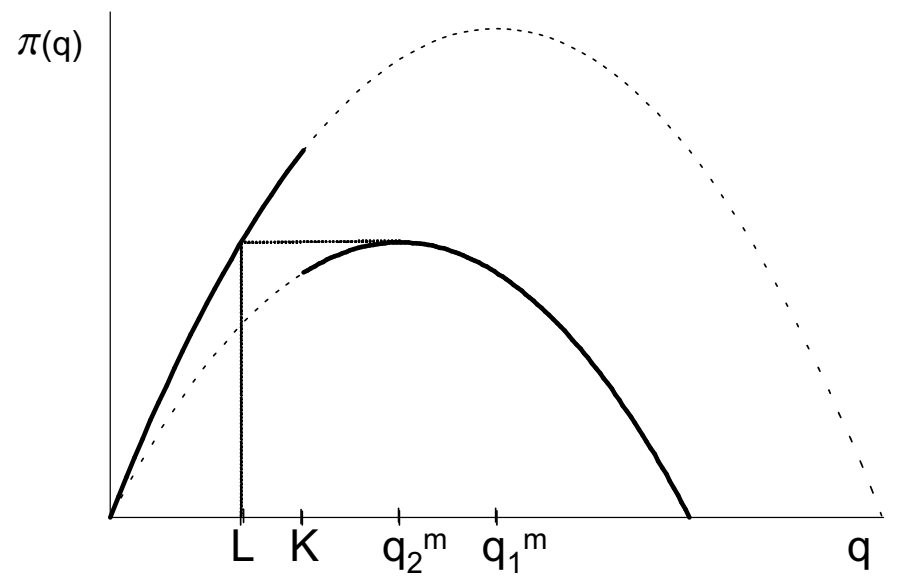

Figure 2: Profit function $\pi(q)$ for intermediate values of $K$.

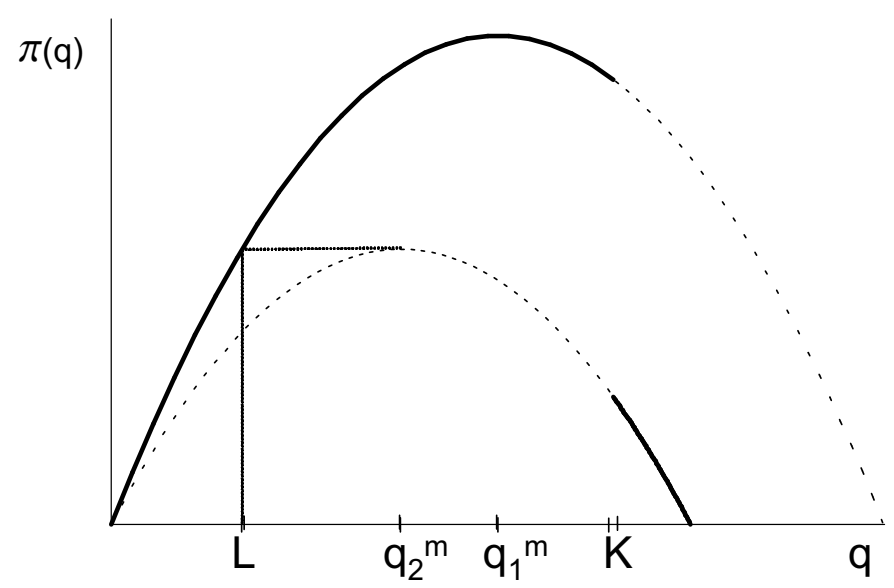

Figure 3: Profit function $\pi(q)$ for high values of $K$. 
the monopoly to get more profit. It actually produces at the optimum the quantity $q_{2}^{m}$ which is optimal for a $c_{2}$-monopoly. This equilibrium will hold as long as the profit obtained by ordering $K$ (at cost $c_{1}$ ) is lower than the profit obtained when producing $q_{2}^{m}$ (at cost $c_{2}$ ). Let us denote $L$ the particular value of $K$ such that the monopoly is indifferent between producing $L$ (at $\operatorname{cost} c_{1}$ ) or $q_{2}^{m}$ (at cost $c_{2}$ ). Given our specifications, $L$ is given by the lower root of

$$
\left(a-b L-c_{1}\right) L=\frac{\left(a-c_{2}\right)^{2}}{4 b} .
$$

Clearly, $L$ is strictly lower than $q_{2}^{m}$ and hence to $q_{1}^{m}$.

Figure 2 presents the case when $K$ is higher than $L$ but also lower than $q_{1}^{m}$, the optimal quantity for a $c_{1}$-monopoly. Here, the optimal quantity is actually $K$. Indeed, as $K>L$, the monopoly earns more by producing $K$ instead of $q_{2}^{m}$. Also, producing less than $K$ is obviously suboptimal because the profit function is increasing as $K$ is lower than $q_{1}^{m}$. In figure $3, K$ goes beyond $q_{1}^{m}$ and the monopoly produces the non constrained optimal quantity $q_{1}^{m}$ bought at $\operatorname{cost} c_{1}$.

Figure 4 depicts the optimal quantity as a function of the low-cost producers capacity $K$.

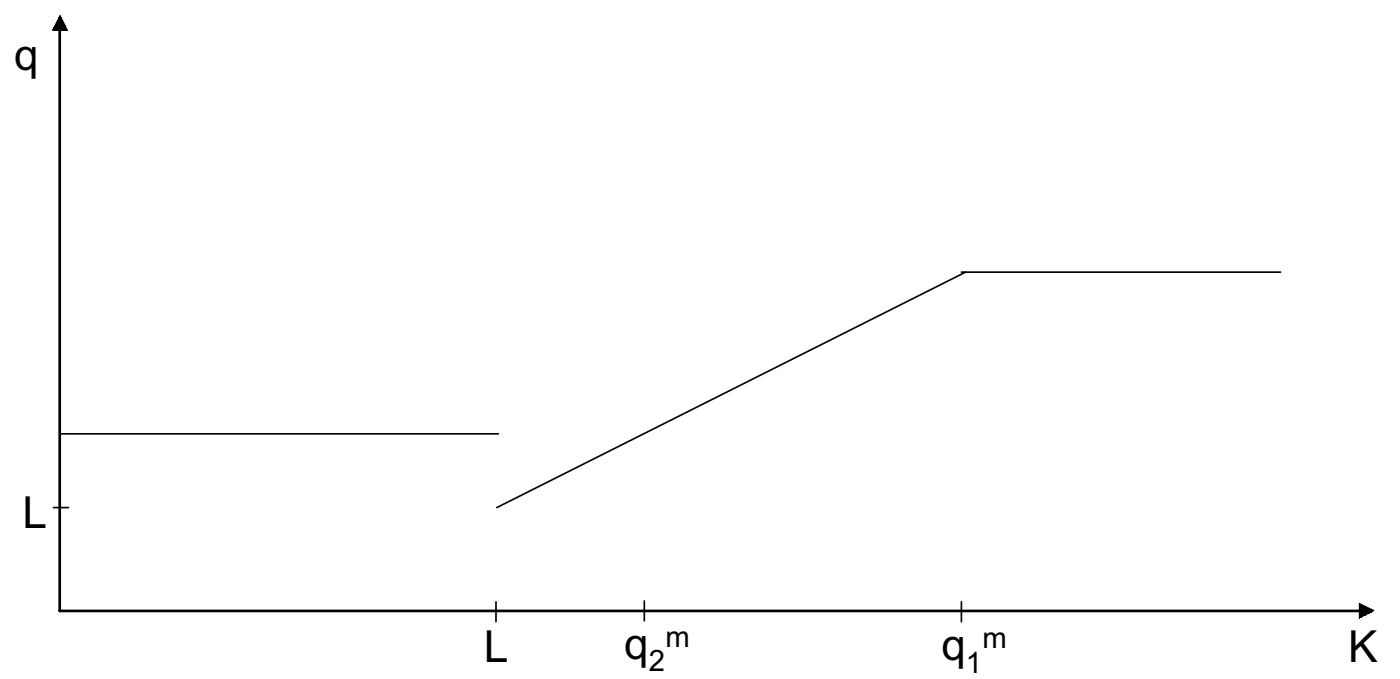

Figure 4: The optimal quantity as a function of the low-cost producers capacity $K$.

When $K$ is low enough, the optimal quantity is $q_{2}^{m}$ and is produced at cost $c_{2}$. When $K$ reaches $L$, there is a discontinuity as the monopoly now prefers to produce $K$ at cost $c_{1}$ until the capacity $K$ goes beyond $q_{1}^{m}$ in which case the optimal quantity remains $q_{1}^{m}$ whatever $K$. Figure 5 depicts the 
corresponding equilibrium price on the final market which presents also a discontinuity when $K=L$.

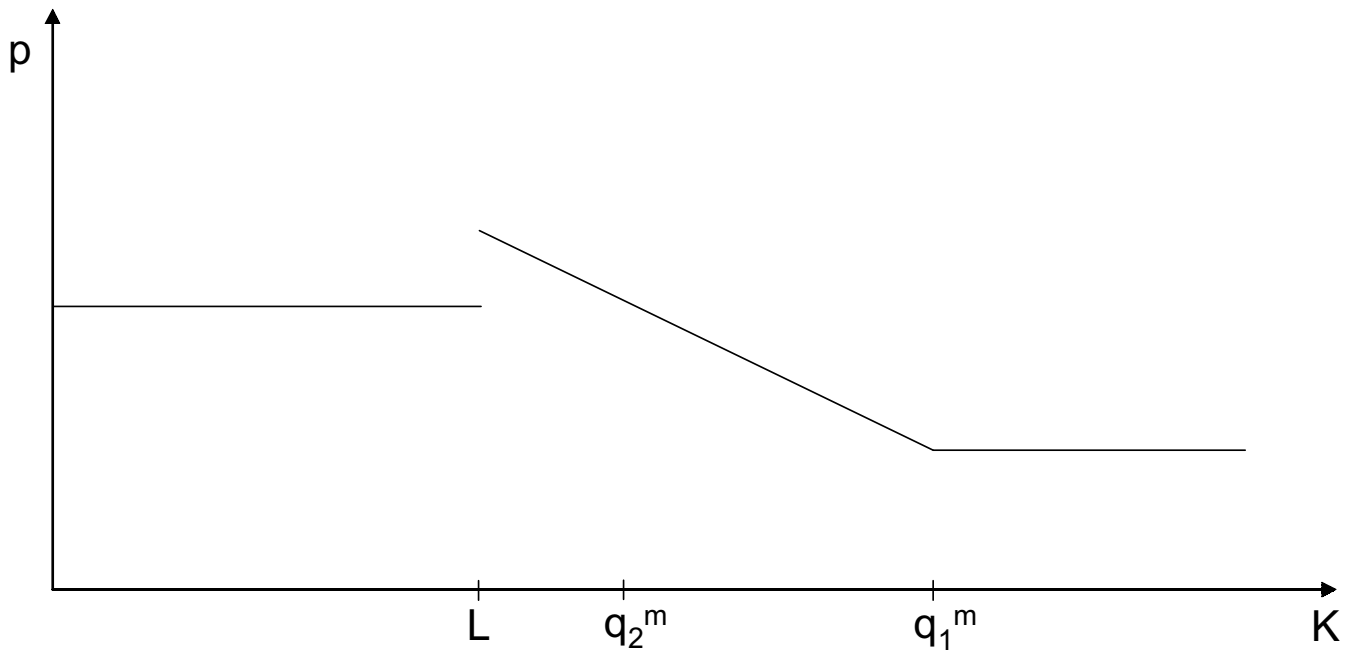

Figure 5: The equilibrium price on the final market as a function of the low-cost producers capacity $K$.

One may interpret an increase in $K$ as an increase in the global efficiency of the upstream sector as a larger quantity could be produced at $\operatorname{cost} c_{1}$. Yet, the jump in the final price implied by the discontinuity is upward. Hence, as soon as $K$ is higher than $L$ but lower than $q_{2}^{m}$, the optimal quantity produced under $\operatorname{cost} c_{1}$ is lower than $q_{2}^{m}$ which is produced at a higher cost $c_{2}$. Consequently, we obtain the counterintuitive result that a (local) increase in the efficiency of the upstream sector might end up with a higher price on the final market. ${ }^{4}$

\section{The oligopoly case}

This section is intended to extend the preceding result to the oligopoly case. We obtain the same result but the proof is different by taking into account the strategic interaction between retailers. This is not surprising as one can view the behavior of an oligopolist as similar to the behavior of a monopolist facing the residual demand, that is the demand left by other members of the oligopoly.

\footnotetext{
${ }^{4}$ If $K$ is subject to random shocks, this might contribute to explain some instability in prices: Even small differences in costs might induce much larger price jumps.
} 


\subsection{Analysis}

We introduce some piece of notations. Recall that $K$ is the total amount of good that can be procured at price $c_{1}$. If total demand exceeds $K$ then all goods have to be paid at price $c_{2}$. From firm $i$ 's viewpoint, when anticipating that other firms will produce a total quantity $Q_{-i}=\sum_{j \neq i} q_{j}$, the good can be procured at the low price $c_{1}$ whenever $q_{i} \leq k_{i}$ where $k_{i}=K-Q_{-i} \cdot{ }^{5}$ In the same spirit, we denote $a_{i}=a-b Q_{-i}$ which represent the maximum admissible price on the residual demand $P_{i}\left(q_{i}\right)=a_{i}-b q_{i}$

\subsubsection{The reaction functions}

Recall that in the monopoly case analyzed above, the threshold $L$ is a function of demand and cost functions parameters (see equation (1)). In particular, $L$ depends on the maximum price $a$. In the oligopoly context, as firm $i$ behaves like a monopoly on its residual demand $P_{i}\left(q_{i}\right)$, it faces a similar trade-off between selling too few products but procured at the low price $c_{1}$ or selling more products but procure at the high price $c_{2}$. As we have seen above in the monopoly context, this trade-of highly depends on the relative position of $K$ and the threshold $L$. In the oligopoly context, this result applies as well but for the residual demand faced by firm $i$ that depends on the others' choices through $Q_{-i}$. Hence, the threshold for firm $i$ depends on $Q_{-i}$ and is denoted $L\left(Q_{-i}\right)$.

Applying equation (1) to the oligopoly context, we have that $L\left(Q_{-i}\right)$ is the solution (lower root) of

$$
\left(a_{i}-b L\left(Q_{-i}\right)-c_{1}\right) L\left(Q_{-i}\right)=\frac{\left(a_{i}-c_{2}\right)^{2}}{4 b}
$$

or equivalently using the definition of $a_{i}$

$$
\left(a-b Q_{-i}-b L\left(Q_{-i}\right)-c_{1}\right) L\left(Q_{-i}\right)=\frac{\left(a-b Q_{-i}-c_{2}\right)^{2}}{4 b}
$$

We now derive the optimal behavior of firm $i$ as a function of competitors' decisions. As in the monopoly case, firm $i$ 's optimal decision depends on the relative position of $k_{i}$ and $L\left(Q_{-i}\right)$. Assume for the moment that $Q_{-i}$ is such that $L\left(Q_{-i}\right) \geq 0$. We thus have three cases:

\footnotetext{
${ }^{5}$ This formulation encompasses the case where $k_{i}$ is non positive. In such a situation, firm $i$ necessarily buys the good at the high price $c_{2}$ (and so is the case for the other members of the oligopoly).
} 
- Case 1: $k_{i}<L\left(Q_{-i}\right)$. Here, the best decision for firm $i$ is to produce the optimal quantity for a monopoly facing the residual demand with the procurement $\operatorname{cost} c_{2}$. Hence, the optimal quantity $q_{i}\left(Q_{-i}\right)$ is such that

$$
q_{i}\left(Q_{-i}\right)=\max \left(0, \frac{a_{i}-c_{2}}{2 b}\right)=\max \left(0, \frac{a-b Q_{-i}-c_{2}}{2 b}\right)
$$

- Case 2: $L\left(Q_{-i}\right) \leq k_{i} \leq \frac{a_{i}-c_{1}}{2 b}=\frac{a-b Q_{-i}-c_{1}}{2 b}{ }^{6}$ In such a situation, firm $i$ prefers to produce the highest quantity $\left(k_{i}\right)$ that can be procured at the low cost $c_{1}$. Hence, $q_{i}\left(Q_{-i}\right)=\max \left(0, k_{i}\right){ }^{7}$

- Case 3: $\frac{a-b Q_{-i}-c_{1}}{2 b}<k_{i}$. Here, firm $i$ is not constrained in buying its ideal quantity given the procurement cost $c_{1}$. Hence, $q_{i}\left(Q_{-i}\right)=\max \left(0, \frac{a_{i}-c_{1}}{2 b}\right)=\max \left(0, \frac{a-b Q_{-i}-c_{1}}{2 b}\right)$.

Actually these results can be generalized to the case where $L\left(Q_{-i}\right)$ is non positive. ${ }^{8}$

\subsubsection{The Nash equilibria}

Having determined the retailers' reaction function, we now look for Nash equilibria. Our strategy is to first characterize Nash equilibria such that one firm at least falls in case 3. Then, we look for Nash equilibria such that one firm at least falls in case 1. Finally we will treat the remaining case when all the firms are in case 2 .

Nash equilibria such that one firm at least falls in case 3 First, suppose that one firm at least, say firm $i$, is in case 3 at equilibrium and hence produces $q_{i}\left(Q_{-i}\right)=\frac{a-b Q_{-i}-c_{1}}{2 b}$. At the equilibrium the good is procured at cost $c_{1}$. Since we have $\frac{a-b Q_{-i}-c_{1}}{2 b}<k_{i}$, any active firm could slightly reduce or increase its quantity without modifying the procurement cost. So, for $q^{*}$ to be a Nash equilibrium, necessarily each individual quantity must be $\frac{a-c_{1}}{(N+1) b}$. This follows from standard

\footnotetext{
${ }^{6}$ Note that similarly to the monopoly situation, $L\left(Q_{-i}\right)$ is lower than $\frac{a_{i}-c_{1}}{2 b}=\frac{a-b Q_{-i}-c_{1}}{2 b}$.

${ }^{7}$ Note that although when $L\left(Q_{-i}\right)>0$, in Case $2 k_{i}$ is necessarily positive, here we take care of the possibility that $k_{i}$ might be non positive. See footnote 8 .

${ }^{8} L\left(Q_{-i}\right)<0$ happens whenever $a_{i}-c_{2}<0$ or equivalently $a-b Q_{-i}-c_{2}<0$. In this situation, others firms produce too much so that the price on the market when firm $i$ is not active is $a-b Q_{-i}<c_{2}$. Hence, if firm $i$ has to procure the good at price $c_{2}$, its best choice is to produce nothing. Moreover, if $k_{i}<0$ then firm $i$ is obliged to procure the good at price $c_{2}$ whatever the quantity and so decides to produce $q_{i}\left(Q_{-i}\right)=0$. This situation appears obviously in Case 1 and in Case 2 when $k_{i}<0$. The above expressions for $q_{i}\left(Q_{-i}\right)$ take into account the fact that $k_{i}<0$ might be non positive. When $k_{i}>0$, firm $i$ 's best choice is to produce a quantity as close to its best response $q_{i}\left(Q_{-i}\right)=\max \left(0, \frac{a-b Q_{-i}-c_{1}}{2 b}\right)$ while still inferior to $k_{i}$. The definition of $q_{i}\left(Q_{-i}\right)$ in Case 2 and 3 are consistent with this behavior. To conclude, the expressions derived in the case $L\left(Q_{-i}\right) \geq 0$ are still valid for the case $L\left(Q_{-i}\right)<0$.
} 
Nash Cournot behavior in a symmetric $N$-oligopoly with constant marginal cost $c_{1}{ }^{9}$ Hence, if one the oligopolists is in case 3 at the equilibrium, it must be true that all firms follow the same behavior. Consequently, we have

$$
\begin{aligned}
& q^{*}=\left(q_{1}^{*}, \ldots, q_{N}^{*}\right) \text { is a Nash equilibrium where one at least of the firms is in case } 3 \\
\Leftrightarrow & q^{*}=\left(q_{1}^{*}, \ldots, q_{N}^{*}\right) \text { is a Nash equilibrium where all firms are in case } 3 \\
\Leftrightarrow & \left\{\begin{array}{c}
q_{i}^{*}=\frac{a-c_{1}}{(N+1) b} \\
\frac{a-b Q_{-i}^{*}-c_{1}}{2 b}<k_{i}
\end{array} \forall i,\right. \\
\Leftrightarrow & \left\{\begin{array}{c}
a-b(N-1) q_{c_{1}}-c_{1} \\
2 b
\end{array} q_{i}^{*}=q_{c_{1}}\right. \\
\Leftrightarrow & \left\{\begin{array}{c}
\forall i, q_{i}^{*}=q_{c_{1}} \\
Q_{c_{1}}<K
\end{array}\right.
\end{aligned}
$$

where $Q_{c_{1}}=\frac{N\left(a-c_{1}\right)}{(N+1) b}$.

Nash equilibria such that one firm at least falls in case 1 Now, let us assume that at least one firm, say firm $i$, is in Case 1 at equilibrium and hence produces $q_{i}\left(Q_{-i}^{*}\right)=\max \left(0, \frac{a-b Q_{-i}^{*}-c_{2}}{2 b}\right)$. At the equilibrium the goods are procured at $\operatorname{cost} c_{2}$. In that case, $K<Q^{*}$ so that any active firm could slightly reduce or increase its quantity without modifying the procurement cost. So, for $q^{*}$ to be a Nash equilibrium, necessarily each individual quantity must be $\frac{a-c_{2}}{(N+1) b}$. This follows from standard Nash Cournot behavior in a symmetric $N$-oligopoly with constant marginal cost $c_{2}$. Hence, if one of the oligopolists is in case 1 at the equilibrium, it must be true that all firms follow the same behavior. Consequently, we have

$$
\begin{aligned}
& q^{*}=\left(q_{1}^{*}, \ldots, q_{N}^{*}\right) \text { is a Nash equilibrium where one at least of the firms is in case } 1 \\
\Leftrightarrow & q^{*}=\left(q_{1}^{*}, \ldots, q_{N}^{*}\right) \text { is a Nash equilibrium where all firms are in case } 1 \\
\Leftrightarrow & \left\{\begin{array}{c}
q_{i}^{*}=\frac{a-c_{2}}{(N+1) b} \\
k_{i}<L\left(Q_{-i}^{*}\right)
\end{array} \forall i\right. \\
\Leftrightarrow & \left\{\begin{array}{r}
\forall i, q_{i}^{*}=q_{c_{2}} \\
K<(N-1) q_{c_{2}}+L\left((N-1) q_{c_{2}}\right)
\end{array}\right.
\end{aligned}
$$

\footnotetext{
${ }^{9}$ If, for an equilibrium candidate, say $\left(\hat{q}_{i}\right)_{i=1 . . N}$, one of the firms is not producing the Cournot output, then the quantities are not a Nash equilibrium of the Cournot game, and at least one firm has incentives to change his quantity given the other firms' quantities. As the profit of a firm, given the other firms' quantities, is a concave function, if a firm $j$ has incentives to choose a different quantity $\widetilde{q}_{j}$, it also prefers any intermediate quantity between $\widetilde{q}_{j}$ and $\hat{q}_{j}$ to the quantity $\hat{q}_{j}$.
} 
Nash equilibria such that all firms fall in case 2 If all firms are in case 2 at equilibrium, then whatever $i, L\left(Q_{-i}^{*}\right) \leq k_{i} \leq q_{c_{1}}$. Consequently, we have

$$
\begin{aligned}
& q^{*}=\left(q_{1}^{*}, \ldots, q_{N}^{*}\right) \text { is a Nash equilibrium where all firms are in case } 2 \\
\Leftrightarrow & \left\{\begin{array}{c}
q_{i}^{*}=k_{i} \\
L\left(Q_{-i}^{*}\right) \leq k_{i} \leq q_{c_{1}} \quad \forall i,
\end{array}\right. \\
\Leftrightarrow & \left\{\begin{array}{c}
\sum_{i} q_{i}^{*}=K \\
\forall i, L\left(Q_{-i}^{*}\right) \leq K-Q_{-i}^{*} \leq q_{c_{1}}
\end{array}\right. \\
\Leftrightarrow & \left\{\begin{array}{c}
\sum_{i} q_{i}^{*}=K \\
\forall i, L\left(Q_{-i}^{*}\right)+Q_{-i}^{*} \leq K \leq q_{c_{1}}+Q_{-i}^{*}
\end{array}\right.
\end{aligned}
$$

Note that in the formulation above, both symmetric and asymmetric equilibria may exist. Restricting the analysis to symmetric equilibria, expression (4) reduces to

$$
\begin{gathered}
\left\{\begin{array}{c}
q_{i}^{*}=\frac{K}{N} \\
L\left(\frac{(N-1) K}{N}\right)+\frac{(N-1) K}{N} \leq K \leq q_{c_{1}}+\frac{(N-1) K}{N}
\end{array} \quad \forall i,\right. \\
q_{i}^{*}=\frac{K}{N} \\
\Leftrightarrow \quad\left\{\begin{array}{c}
N\left(\frac{(N-1) K}{N}\right)+\frac{(N-1) K}{N} \leq K \leq Q_{c_{1}}
\end{array} \quad \forall i .\right.
\end{gathered}
$$

All Nash equilibria To sum up our results, let us denote

$$
\varphi_{N}(x)=L\left(\frac{(N-1) x}{N}\right)+\frac{(N-1) x}{N} .
$$

Then, we get

$$
\left\{\begin{array}{c}
\left(q_{c_{2}}, q_{c_{2}}, \ldots, q_{c_{2}}\right) \text { is a Nash equilibrium as soon as } K \leq \varphi_{N}\left(Q_{c_{2}}\right) \\
\left(\frac{K}{N}, \frac{K}{N}, \ldots, \frac{K}{N}\right) \text { is a Nash equilibrium as soon as } \varphi_{N}(K)<K<Q_{c_{1}} \\
\left(q_{c_{1}}, q_{c_{1}}, \ldots, q_{c_{1}}\right) \text { is a Nash equilibrium as soon as } Q_{c_{1}} \leq K
\end{array}\right.
$$

As in the monopoly case, for small values of $K$, competition mimics the situation that would occur in a symmetric high-cost $N$-oligopoly while for large values of $K$, we obtain the outcome of a symmetric low-cost $N$-oligopoly. For intermediate values of $K$, the situation where firms share $K$ between themselves in order to secure the good at a low cost is a Nash equilibrium of the game. Now, the interesting issue is to analyze the different patterns of equilibria. This is done in the proof of the following proposition.

Proposition 1 There exist $\mathcal{L}_{1}$ and $\mathcal{L}_{2}$ such that $0<\mathcal{L}_{1}<\mathcal{L}_{2}<Q_{c_{2}}$ and such that

(i) when $K<\mathcal{L}_{1}$, the only Nash equilibrium is $\left(q_{c_{2}}, \ldots, q_{c_{2}}\right)$, 
(ii) when $\mathcal{L}_{1} \leq K \leq \mathcal{L}_{2}$, there are two symmetric Nash equilibria, $\left(q_{c_{2}}, \ldots, q_{c_{2}}\right)$ and $\left(\frac{K}{N}, \ldots, \frac{K}{N}\right)$. However, the equilibrium $\left(\frac{K}{N}, \ldots, \frac{K}{N}\right)$ dominates the other one,

(iii) when $\mathcal{L}_{2}<K \leq Q_{c_{1}}$, the only symmetric Nash equilibrium is $\left(\frac{K}{N}, \ldots, \frac{K}{N}\right)$,

(iv) when $Q_{c_{1}}<K$, the only Nash equilibrium is $\left(q_{c_{1}}, \ldots, q_{c_{1}}\right)$.

When $\mathcal{L}_{1} \leq K \leq Q_{c_{1}}$, if $\left(q_{1}^{*}, \ldots, q_{N}^{*}\right)$ is a Nash equilibrium, then $\sum_{i} q_{i}^{*}=K$.

Moreover, we have $\mathcal{L}_{2}=\varphi_{N}\left(Q_{c_{2}}\right)$ and $\mathcal{L}_{1}$ is the (unique) solution of $\varphi_{N}\left(\mathcal{L}_{1}\right)=\mathcal{L}_{1}$.

Proof: See Appendix A.

\begin{tabular}{|c|c|c|c|}
\hline \multicolumn{2}{|c|}{$\mathfrak{L}_{1}$} & $\mathfrak{L}_{2} \quad \mathrm{Q}_{\mathrm{c} 2}$ & $c 1$ \\
\hline$\left(\mathrm{q}_{\mathrm{c} 2}, \mathrm{q}_{\mathrm{c} 2}, \ldots, \mathrm{q}_{\mathrm{c} 2}\right)$ & $\begin{array}{c}\left(\mathrm{q}_{\mathrm{c} 2}, \mathrm{q}_{\mathrm{c} 2}, \ldots, \mathrm{q}_{\mathrm{c} 2}\right) \\
(\mathrm{K} / \mathrm{N}, \mathrm{K} / \mathrm{N}, \ldots, \mathrm{K} / \mathrm{N}) \\
\text { And some other } \\
\left(\mathrm{q}_{1}, \mathrm{q}_{2}, \ldots, \mathrm{q}_{\mathrm{N}}\right) \text { such that } \\
\mathrm{q}_{1}+\mathrm{q}_{2}+\ldots+\mathrm{q}_{\mathrm{N}}=\mathrm{K}\end{array}$ & $\begin{array}{c} \\
(\mathrm{K} / \mathrm{N}, \mathrm{K} / \mathrm{N}, \ldots, \mathrm{K} / \mathrm{N}) \\
\text { And some other } \\
\left(\mathrm{q}_{1}, \mathrm{q}_{2}, \ldots, \mathrm{q}_{\mathrm{N}}\right) \text { such that } \\
\mathrm{q}_{1}+\mathrm{q}_{2}+\ldots+\mathrm{q}_{\mathrm{N}}=\mathrm{K}\end{array}$ & $\left(\mathrm{q}_{\mathrm{c} 1}, \mathrm{q}_{\mathrm{c} 1}, \ldots, \mathrm{q}_{\mathrm{c} 1}\right)$ \\
\hline
\end{tabular}

Figure 6: The set of Nash equilibria according to the value of $K$.

Note that Proposition 1 indicates that asymmetric equilibria may only occur for values of $K$ where a symmetric equilibrium $\left(\frac{K}{N}, \ldots, \frac{K}{N}\right)$ also exists. What is important actually is that the total quantity on the market is $K$ for both types of equilibria. So, similarly to the monopoly case, we can draw Figure 4 depicting the equilibrium quantity as a function of the low-cost producers capacity $K$. When $K$ is low enough, the equilibrium quantity is $Q_{c_{2}}$ and is produced at cost $c_{2}$. When $K$ reaches $\mathcal{L}_{1}$, there is a discontinuity as the oligopolists now prefer to produce $K / N$ at $\operatorname{cost} c_{1}$ if their competitors produce $K / N$. This remains true until the capacity $K$ goes beyond $Q_{c_{1}}$ in which case the equilibrium quantity 
remains $Q_{c_{1}}$ whatever $K$. Figure 5 depicts the corresponding equilibrium price on the final market which presents an upward discontinuity when $K=\mathcal{L}_{1}$. Still, we obtain the following counterintuitive result.

Corollary 2 A local increase in the efficiency of the upstream sector might end up with a higher price on the final market.

\subsection{Comparative statics}

In this subsection, we specifically investigate the impact of an increase in the size $N$ of the oligopoly.

\subsubsection{Impact of $N$ on prices}

First, it is clearly seen that $Q_{c_{1}}$ and $Q_{c_{2}}$ are increasing in $N$. Recall that $\mathcal{L}_{1} \equiv \mathcal{L}_{1}(N)$ is such that

$$
\varphi_{N}\left(\mathcal{L}_{1}(N)\right)=\mathcal{L}_{1}(N) .
$$

As $\varphi_{N+1}(x) \geq \varphi_{N}(x)$ whatever $x$ non negative, and $\varphi_{N}$ is increasing,

$$
\mathcal{L}_{1}(N+1) \geq \mathcal{L}_{1}(N)
$$

It follows that the total quantity sold on the market is increasing in $N$, and hence the retail price is decreasing in $N$.

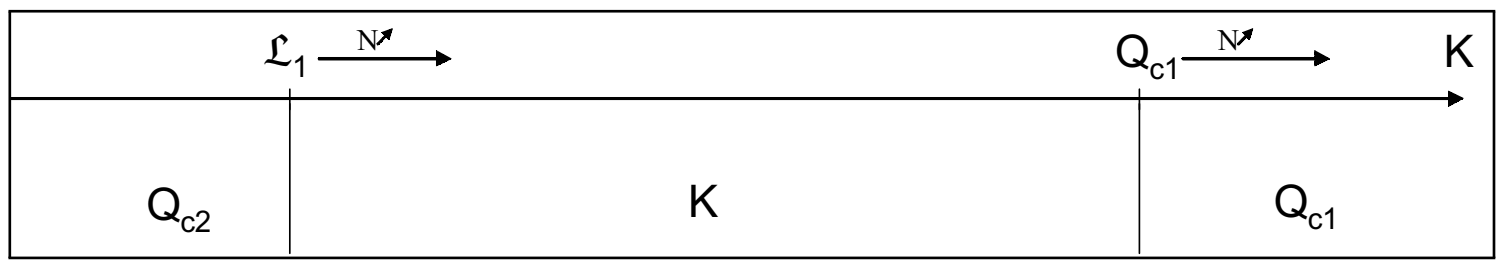

Figure 7: The total quantity according to the relative situation of $K, Q_{c_{1}}$ and $\mathcal{L}_{1}(N)$.

Indeed, as long as $K$ remains in one of the three zones depicted in the figure 7, the total quantity is non decreasing in $N$. One can check that the total quantity change is positive when the increase in $N$ implies that $K$ goes from one zone to another. Suppose for example that for a given $N$, $\mathcal{L}_{1}(N)<K<\mathcal{L}_{1}(N+1)$. Then, the quantity produced with $N+1$ retailers is $Q_{c_{2}}(N+1)$, which has 
been shown to be higher than $\mathcal{L}_{1}(N+1)$, and is therefore higher than the quantity $K$ produced with $N$ retailers.

For a given value of $K$, as $N$ increases, there is less chance that oligopolists collectively restrain to produce $K$ in order to benefit from a low procurement price $c_{1}$. Thus the procurement price is increasing in $N$. This explains why upstream producers might benefit from increased competition downstream.

\subsubsection{Impact of $N$ on profits}

As expected, retailers total profit is naturally decreasing in $N .{ }^{10}$ Nevertheless, it may happen that the industry (retailers plus upstream sector) profit may increase. Indeed, the increase in the upstream sector profit (due to an increasing upstream price) may outweigh the decrease of the retailers profit when $N$ raises. In the following proposition, we exhibit this phenomenon by looking at the impact of going from a retailer monopolist to a duopoly structure.

Proposition 3 There exist some values of $K$ for which the total profit of the industry (retail plus upstream sectors) strictly increases when $N$ goes from 1 to 2 , if and only if $\frac{a-c_{2}}{a-c_{1}} \leq \frac{12}{13}$. More precisely the relevant set of $K$ is then given by $\left[\mathcal{L}_{1}(1), \min \left\{\mathcal{L}_{1}(2),\left(a-c_{2}\right) / 3 b\right\}\right)$.

\section{Proof: See Appendix B.}

\section{Concluding remarks}

As we have seen, our main result states that a (marginal) increase in the efficiency of the upstream sector may have adverse effects on the retail price, whether the downstream sector consists in a monopoly or an oligopoly. As suggested in the introduction, there are many ways to interpret an increase in the upstream sector's efficiency.

\footnotetext{
${ }^{10}$ To prove this, note that retailers' total profit for a given total quantity $Q$ is equal to a monopolist retailer's profit producing $Q$.

When $K$ does not belong to $\left[\mathcal{L}_{1}(1), q_{2}^{m}\right]$, the monopolist profit is decreasing in the quantity sold, as long as it is higher than the optimal monopoly quantity. As the total quantity sold on the market is increasing in $N$, this proves that the retailers total profit is decreasing in $N$.

When $K$ belongs to $\left[\mathcal{L}_{1}(1), q_{2}^{m}\right]$, retailers offer a quantity $K$ on the market for low $N$, and switch to the Cournot equilibrium quantities given a procurement $\operatorname{cost} c_{2}$ when $N$ is high enough. These quantities are above $q_{2}^{m}$, and thus belong to a region where the monopolist profit is decreasing in the quantity sold. As the total profit of the retail sector when producing $K$ is higher than any profit the retailers can get with a procurement $\operatorname{cost} c_{2}$, we still obtain that the retailers total profit is decreasing in $N$ in this case.
} 
First, the heterogeneity of the upstream sector might result from regulatory intervention. For instance assume that all upstream producers face the same production conditions and hence a same marginal cost $c_{2}$. Suppose that the regulator subsidizes some of the producers by an amount $s \equiv c_{2}-c_{1}$ per unit produced up to some limit such that the total subsidized quantity is $K$. The reason why the regulator might want to subsidize (partly) production is left unmodelled. If $K$ is small, then the intervention does not impact the downstream market and subsidized producers keep the whole subsidy. On the contrary, when $K$ is large, then the outcome is the same as if all producers were facing the same marginal $\operatorname{cost} c_{1}$ and consequently the whole subsidy is perfectly transferred to the downstream sector (including consumers). Finally, for intermediate values of $K$, retailers prefer to limit their production to subsidized quantity $K$, the total subsidy is perfectly transferred to them. This phenomenon appears as soon as $K$ is taking values between $\mathcal{L}_{1}$ and $Q_{c_{1}}$. Furthermore, if $K$ is taking values between $\mathcal{L}_{1}$ and $Q_{c_{2}}$, consumers suffer from price increase compared to the no regulation situation, and the social surplus decreases.

Now suppose that the total quantity which is subsidized is fixed to $K$. The regulator decides on the level of $s$. If one increases $s$, there are two consequences: first, the threshold $\mathcal{L}_{1}$ at which the retailers prefer to stick to total subsidized production $K$ is decreasing so that the upward jump on the final price comes for lower values of $K$, and second, as a consequence, the upward jump in final price is also higher. This is detrimental for consumers and can also be detrimental for upstream producers if this increase in $s$ causes $K$ to exceed $\mathcal{L}_{1}$, as their rent is then fully transferred to the retailers.

Second, the framework may be interpreted in an international context. For this, assume that domestic production capacity is $K$ with marginal cost $c_{1}$ and that the market can be supplied by foreign producers that suffer from a cost disadvantage. The gap $c_{2}-c_{1}$ between foreign and domestic marginal costs may come from a combination of less efficient technologies abroad, the presence of tariffs and transportation costs. Our analysis suggests that an increase in cheaper domestic production might not be in the interest of (domestic) consumers. Conversely, suppose that domestic production $\left(c_{2}\right)$ is now costlier than foreign production $\left(c_{1}\right)$ but that there is an import quota $K$ in order to protect domestic producers. If one has to increase the import quota for whatever reason, this can be harmful 
for consumers.

Third, an increase in $K$ might come from the fact that the upstream producers get increasing availability of more efficient technologies through some investment, so that some of them switch from marginal cost $c_{2}$ to $c_{1}$. As soon as total production capacity $K$ (at cost $c_{1}$ ) is not too large, efficient individual producers are rewarded at a rate $c_{2}-c_{1}$. If this allows them to compensate for the cost of investment, there will exist a marginal (myopic) producer who, by investing, will have a large impact on the market, as the procurement price will now reach $c_{2}$, thereby expropriating all efficient producers from their investment. This will also provoke an (brutal) increase in final price. As the benefit from investing is captured by retailers as soon as $K$ is higher than $\mathcal{L}_{1}$, producers no longer have incentives to invest whereas it would be welfare improving. ${ }^{11}$

An interesting extension of the model would amount to consider that the total capacity $K$ is endogenously determined at the equilibrium by rational upstream producers who can undertake costreducing investments. This task is devoted to future research.

\footnotetext{
${ }^{11}$ Of course, this argument might not hold when upstream producers have market power.
} 


\section{References}

[1] Bulow, J. I., and P. Pfleiderer (1983): "A note on the effect of cost changes on prices," Journal of Political Economy, 91, 182-185.

[2] Hamilton, S. F., and D. L. Sunding (1998): "Returns to public investments in agriculture with imperfect downstream competition," American Journal of Agricultural Economics, 80(4), 830-838.

[3] Ten Kate, A. , and G. Niels (2005): "To what extent are cost savings passed on to consumers. An oligopoly approach," European Journal of Law and Economics, 20, 323-337.

[4] Pindyck, R., and D.L. Rubinfeld (2005). Microeconomics 6e. Prentice Hall.

[5] Barros, P. P., Brito, D., and D. de Lucena (2006): "Mergers in the food retailing sector: An empirical investigation," European Economic Review, 50, 447-468.

[6] Stennek, J., and F. Verboven (2001): "Merger control and enterprise competitiveness," The Research Institute of Industrial Economics, working paper 556. 


\section{Appendix}

\section{A Proof of Proposition 1}

First we study the function $\varphi_{N}(x)$. Using the properties of this function, we rearrange (6) in order to get parts (i) to (iv). Then, we show that the case described in part (ii), one equilibrium dominates the other one.

From (3), recall that $L(x)$ is given by

$$
\left(a-b x-b L(x)-c_{1}\right) L(x)=\frac{\left(a-b x-c_{2}\right)^{2}}{4 b} .
$$

Differentiating this equation w.r.t. $x$, we obtain that:

$$
L^{\prime}(x)=-\frac{1}{2}\left[\frac{a-c_{2}-b x-2 b L(x)}{a-c_{1}-b x-2 b L(x)}\right] .
$$

Both terms of the fraction are positive ${ }^{12}$ and furthermore the term between brackets is inferior to 1.

Then it is true that $-\frac{1}{2} \leq L^{\prime}(x) \leq 0 .{ }^{13}$

Recall also that $\varphi_{N}(x)=L\left(\frac{(N-1) x}{N}\right)+\frac{(N-1) x}{N}$. Differentiating w.r.t. $x$, we get

$$
\varphi_{N}^{\prime}(x)=\frac{N-1}{N}\left[L^{\prime}\left(\frac{(N-1) x}{N}\right)+1\right],
$$

so it is also true that

$$
\frac{1}{2} \frac{N-1}{N} \leq \varphi_{N}^{\prime}(x) \leq \frac{N-1}{N}<1 .
$$

A direct consequence of this result is that the function $\varphi_{N}(x)-x$ is strictly decreasing and $\lim _{x \rightarrow+\infty} \varphi_{N}(x)-x=-\infty$. Moreover, as $\varphi_{N}(0)>0$, the equation $\varphi_{N}(x)-x=0$ has a unique (positive) solution so that the function $\varphi_{N}(x)-x$ is first positive, reaches zero at $x \equiv \mathcal{L}_{1}$ and then is negative.

From (6), the condition $\varphi_{N}(K)<K<Q_{c_{1}}$, upon which $\left(\frac{K}{N}, \ldots, \frac{K}{N}\right)$ is a Nash equilibrium, can be rewritten as $\mathcal{L}_{1}<K<Q_{c_{1}}$. Denoting $\mathcal{L}_{2}=\varphi_{N}\left(Q_{c_{2}}\right)$, we obtain the different regimes described in

\footnotetext{
${ }^{12}$ See footnote 6 .

${ }^{13}$ As said earlier when presenting the model, our results can be generalized to demand functions such that that whatever $Q$ and $q$ positive, we have $q P^{\prime \prime}(q+Q)+P^{\prime}(q+Q) \leq 0$. This assumption is needed here to garantee that $L^{\prime}(x) \leq 0$.
} 
parts (i) to (iv). Moreover, if $\mathcal{L}_{1}<K<Q_{c_{1}}$, as indicated by the above study and in particular (4), other potential asymmetric equilibria require that $\sum_{i} q_{i}^{*}=K$.

Now, we have to prove that $\mathcal{L}_{1}<\mathcal{L}_{2}<Q_{c_{2}}$. First let us show that $\mathcal{L}_{2}<Q_{c_{2}}$. Assume that $K=Q_{c_{2}}-\varepsilon$ with $\varepsilon>0$. Suppose that all players except player 1 choose $q_{c_{2}}$. If $\mathcal{L}_{2} \geq Q_{c_{2}}-\varepsilon$ then player 1 would want to play $q_{c_{2}}$ rather than $q_{c_{2}}-\varepsilon$. However, by choosing $q_{c_{2}}-\varepsilon$ instead of $q_{c_{2}}$, player 1 would loose a revenue less than a $\varepsilon$ but would gain more than $\left(q_{c_{2}}-\varepsilon\right)\left(c_{2}-c_{1}\right)$. So for $\varepsilon$ small enough, player 1 prefers $q_{c_{2}}-\varepsilon$ to $q_{c_{2}}$ and so $\mathcal{L}_{2}<Q_{c_{2}}-\varepsilon$. Consequently, $\mathcal{L}_{2}=\varphi_{N}\left(Q_{c_{2}}\right)<Q_{c_{2}}$. As $\varphi_{N}(x)-x$ is non increasing and $\varphi_{N}\left(\mathcal{L}_{1}\right)=\mathcal{L}_{1}$ we have $Q_{c_{2}}>\mathcal{L}_{1}$. Moreover, as $\varphi_{N}($.$) is non$ decreasing, we get $\varphi_{N}\left(Q_{c_{2}}\right)>\varphi_{N}\left(\mathcal{L}_{1}\right)$, that is $\mathcal{L}_{2}>\mathcal{L}_{1}$.

It remains to show that for $\mathcal{L}_{1} \leq K \leq \mathcal{L}_{2}$, the equilibrium $\left(\frac{K}{N}, \ldots, \frac{K}{N}\right)$ dominates the equilibrium $\left(q_{c_{2}}, \ldots, q_{c_{2}}\right)$. As $\left(\frac{K}{N}, \ldots, \frac{K}{N}\right)$ is a Nash equilibrium, we must have that for say player $1, \pi_{1}\left(\frac{K}{N}, \ldots, \frac{K}{N}\right) \geq$ $\pi_{1}\left(q_{c_{2}}, \frac{K}{N}, \ldots, \frac{K}{N}\right)$. Moreover, as a firm's profit for a given individual quantity is decreasing in the total quantity chosen by the others and as we have here $K<Q_{c_{2}}$ or equivalently $\frac{K}{N}<\frac{Q_{c_{2}}}{N}=q_{c_{2}}$, it is true that $\pi_{1}\left(q_{c_{2}}, \frac{K}{N}, \ldots, \frac{K}{N}\right)>\pi_{1}\left(q_{c_{2}}, \ldots, q_{c_{2}}\right)$. This concludes the proof.

\section{B Proof of Proposition 2}

To obtain the desired result, it must be true that when going from the monopoly to the duopoly structure, the upstream sector total profit must raise and this can only comes from an increase in the procurement price from $c_{1}$ to $c_{2}$. Recall that the necessary and sufficient condition for the procurement price to be $c_{1}$ in the monopoly case $(N=1)$ is $K \geq \mathcal{L}_{1}(1)$. Similarly, the procurement price is $c_{2}$ in the duopoly case if and only if $K<\mathcal{L}_{1}(2)$. We assume that both conditions hold in the following. Hence, for $N=1$, the total quantity offered to consumers is $K$ while it is $Q_{c_{2}}(2)=2\left(a-c_{2}\right) / 3 b$ in the duopoly case.

Moreover, note that the total industry profit $\Pi^{\text {tot }}$ whatever $N$ can be written as follows:

$$
\text { for } Q \geq K, \Pi^{t o t}=\left(a-c_{2}-b Q\right) Q+\left(c_{2}-c_{1}\right) K
$$

So, the total profit when producing $Q_{c_{2}}(2)$ is greater than the total profit when producing $K$ if 
and only if

$$
\left(a-c_{2}-b K\right) K<\left(a-c_{2}-b Q_{c_{2}}(2)\right) Q_{c_{2}}(2)
$$

which is satisfied when $K<\left(a-c_{2}\right) / 3 b$.

We thus obtain the desired result if and only if $K \in\left[\mathcal{L}_{1}(1), \min \left(\mathcal{L}_{1}(2),\left(a-c_{2}\right) / 3 b\right)[\right.$. It remains to determine the parameters values for which this set is non empty. First note that as shown before, $\mathcal{L}_{1}(2)>\mathcal{L}_{1}(1)$. As the function $g(q)=q\left(a-c_{1}-b q\right)$ is strictly increasing on $\left[0, \frac{a-c_{1}}{2 b}\right]$, then $L=$ $\mathcal{L}_{1}(1) \leq\left(a-c_{2}\right) / 3 b$ is equivalent to

$$
\frac{a-c_{2}}{3 b}\left(a-c_{1}-b \frac{a-c_{2}}{3 b}\right) \geq L\left(a-c_{1}-b L\right)=\frac{\left(a-c_{2}\right)^{2}}{4 b}
$$

which yields to $13 c_{2}-12 c_{1} \geq a$, or equivalently

$$
\frac{a-c_{2}}{a-c_{1}} \leq \frac{12}{13}
$$

